\title{
Seismic Driven Geomechanical Modeling of Uplifted and Subsided Wells in Mumbai Offshore and Its Engineering Implications
}

\author{
Venkatesh Ambati \\ Computational Petroleum Geomechanics Laboratory, \\ Department of Ocean Engineering, \\ Indian Institute of Technology Madras, Chennai, India. \\ E-mail: oe16d0204@smail.iitm.ac.in \\ Nagendra Babu Mahadasu \\ Computational Petroleum Geomechanics Laboratory, \\ Department of Ocean Engineering, \\ Indian Institute of Technology Madras, Chennai, India. \\ E-mail: oe16d022@smail.iitm.ac.in \\ Rajesh R. Nair \\ Computational Petroleum Geomechanics Laboratory, \\ Department of Ocean Engineering, \\ Indian Institute of Technology Madras, Chennai, India. \\ Corresponding author: rajeshnair@iitm.ac.in
}

(Received on May 3, 2021; Accepted on May 12, 2021)

\begin{abstract}
Seismic data provide evidence about hydrocarbon deposition, geological and geophysical subsurface information, including geomechanical aspects. Deriving and understanding geomechanical properties is crucial for reservoir management as it can avoid drilling and production-related problems that cause environmental impacts associated with land subsidence and uplift. The Poison's ratio (PR), Young Modulus (YM), and elastic moduli for a reservoir block were estimated using 3D seismic pre-stack data and well data. 3D Mechanical Earth Models (MEM) were also developed using the well logs, seismic horizons, and drilling data. Seismic data-derived geomechanical properties were compared with the mechanical earth models for the first time for this field. Well-tie analysis was used for inversion of 3D seismic data to extract detailed waveform and amplitude information. The brittleness index of the subsurface layers was estimated, which is a critical rock property that provides information about rock hardness and fragility phenomenon. The brittleness index has a diverse range from 5-35\%, with significant contrast at shallow zones. PR and YM models generated from 3D MEM and seismic data have average values of $0.2-0.6$ and $5-28 \mathrm{GPa}$ with significant contrast from shales and carbonates. The study recommends that the drilling through these problematic zones should be avoided to avoid wellbore problems that cause challenges in maintaining wellbore integrity and reservoir management in the North-Heera field, Mumbai Offshore Basin.
\end{abstract}

Keywords- Seismic inversion, Well-tie analysis, Geomechanical properties, Mechanical earth models, Reservoir management.

\section{Introduction}

Oil and gas drilling and production from offshore fields are always associated with high environmental risks. There are sequential phases (drilling, production/injection, well-intervention jobs, hydrofracturing) in oil field development, and there are different risk factors for each phase (Rana, 2008). Big oil companies invest billions in safety and to reduce environmental risks. Though pinnacle safety measures were followed, we witnessed catastrophic oil and gas drilling disasters, from the Piper Alfa (1988) to Deepwater Horizon (2010) tragedies, causing damage to human life 
and the environment. Most oil and gas accidents are caused mainly by human error or misinterpretation of subsurface pressures. Drilling through abnormal zones and missing the planned well trajectories causes immediate problems as well as later effects like wellbore collapse and land subsidence. An appropriate multi-dimensional geomechanical study based on different data which investigates the causes of past accidents can address drilling problems and minimize/avoid associated environmental risks. In recent years, the importance of geomechanical studies increased worldwide. Geomechanical analysis of wellbore and reservoir systems has to undergo the appraisal stage to the abandonment stage - is essential to avoid/address drilling and production-related issues. Proper geomechanical analysis can avoid catastrophic events during drilling and field development by identifying the weak zones and abnormal pressure zones. Geomechanics supports geophysical studies, mainly drilling and reservoir engineering. Studies of both shallow and deeper subsurface fare always associated with in-situ stresses. The precise calculation and analysis of the in-situ stress help improve drilling engineering and reservoir engineering aspects.

In-situ rock properties are estimated from the elastic waves from seismic data and well logs (Fjaer et al., 1992). Loading tests and ultrasonic tests from the laboratory provide static and dynamic elastic properties of a rock. There are many complications involved in reservoir geomechanical studies, and one of them is the availability of the data (Dusseault, 2011). Though rock properties are calculated from seismic data, well logs, drilling data, and lab tests individually, an integrated approach to estimate and analyze geomechanical properties is always preferable. Seismic waves provide lateral information about the subsurface where the survey was carried out.

A seismic survey is a constant tool for subsurface mapping and characterization from exploration to abandonment. Mechanical properties of the rock are estimated from the compressional waves and shear waves of the recorded seismic data. Synthetic acoustic waves are generated from the 3D seismic data using well-tie analysis. In this study, we inverted 3D pre-stack seismic data of the North-Heera field. In general, seismic sources on the ground generate mechanical waves that travel through the layers of the formation and can be reflected and recorded by the geophones (receivers) placed at a desirable distance from the source on the surface (Talwani and Kessinger, 2003). Twoway travel time is the generated seismic wave's time to travel from the source to the receiver after reflecting at the subsurface layers. Recorded reflection seismic survey data have several seismic traces. A single seismic trace consists of the seismic wave's energy traveled in the earth's crust recorded at a single geophone/hydrophone (receiver) shown in Figure 1(b).

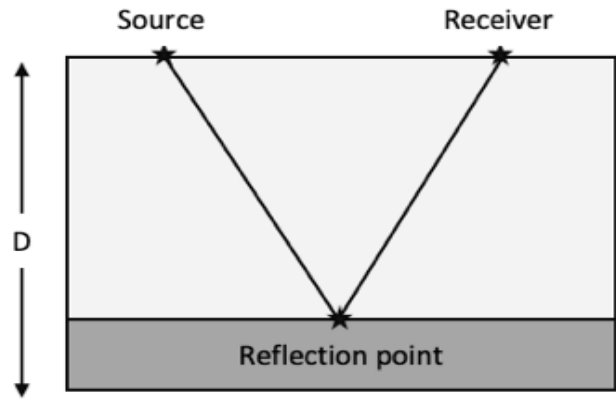

(a)

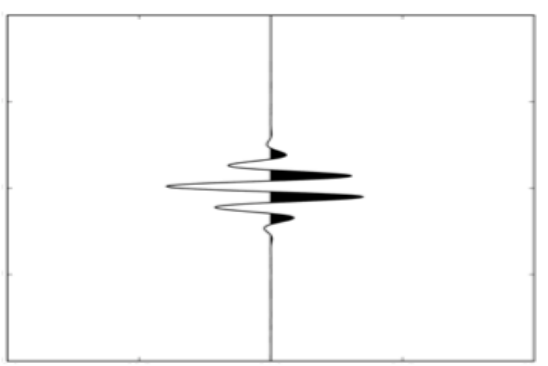

(b)

Figure 1. (a) Shows the typical travel path of a seismic wave from source to the receiver via subsurface, (b) a single seismic trace with energy in it. 
Multiple shots were recorded in a seismic reflection survey by different methods. One example is common midpoint (CMP) gathering. The traces were corrected for Normal Move Out (NMO) and combined using CMP for recorded seismic traces to enhance noise to signal ratio. 3D seismic acquisition is advantageous in geological structure imaging and adequate subsurface sampling for defining geological aspects. In a 3D survey of the area of interest, the source and geophones were moved in $\mathrm{x}$-line and cross-line to complete a grid. 3D pre-stack data undergo almost the same stages as the $2 \mathrm{D}$ seismic data processing methods but are complicated with $3 \mathrm{D}$ geometry, migration, and velocity analysis. Well-seismic data tie generates more stable velocity distributions, which helps determine the in-situ geomechanical properties of the basin/field (Dutta, 2002). Despite the difference in seismic and $\log$ velocities frequency, well-seismic ties create a relation between velocity and time at a well location (Soleymani and Riahi, 2012). Velocities are extracted from the generated velocity cube using seismic sections. The advantage of 3D seismic data is that faults and formations horizons are mapped accurately, which is considered to generate geomechanical properties. On the other end, geomechanical properties calculated using well logs provide almost the same results with minor variations in values. Hence the comparison of geomechanical properties from seismic and well logs gives field applicable geomechanical analysis. Well logs such as sonic, density, caliper, gamma, and electrical logs are primary inputs for developing 1D Mechanical Earth Models (MEM). Seismic horizons and fault lines, including 1D MEMs, are vital parameters for developing 3D MEMs. The Mechanical Earth Model is a numerical representation of the state of stress and rock mechanical properties for a specific stratigraphic section in a field or basin. Sedimentary rock elastic moduli, Poisson's ratio, internal friction angle, Brittleness Index (BI), and Unconfined Compressive Strength (UCS) are estimated and analyzed from geomechanical properties for studying weak zones and subsidence of the platforms and wells. In this study, geomechanical properties estimated from seismic data and well logs are compared and studied for an area of more than 200 sq. km of the North-Heera field, India.

\section{Methodology}

\subsection{Field Geological Information}

This study is based on 3D seismic data and well logs are from the North-Heera field, located on the western offshore of India, as shown in Figure 2(a). This is one of the largest oil and gas producing fields in India. A few wells and platforms from this offshore field have encountered subsidence (Figure 2(b)) and upliftment (Figure 2(c)), causing substantial financial loss. This sedimentary basin is characterized by alternative sedimentary deposition of shale and carbonate layers. Shallow layer lithology consists of mainly shale and claystone from late Miocene to Holocene of an average thickness of $600 \mathrm{~m}$ with an average water depth of $30 \mathrm{~m}$ at this block. Source rock is from the tertiary epochs Paleocene to middle Miocene and composed of mainly carbonate (limestone) layers with moderate yellow and a combination of yellow-green fluorescence. In this block, there are 8 formation layers from the seabed to the basement. Formation-1 is mainly composed of shale and claystone with gamma values of 55API and above. Formation-2 is limestone having vugular porosity, where formation-3 is a thin shale layer followed by layer (formation-4) with a mixture of shale and limestone. 

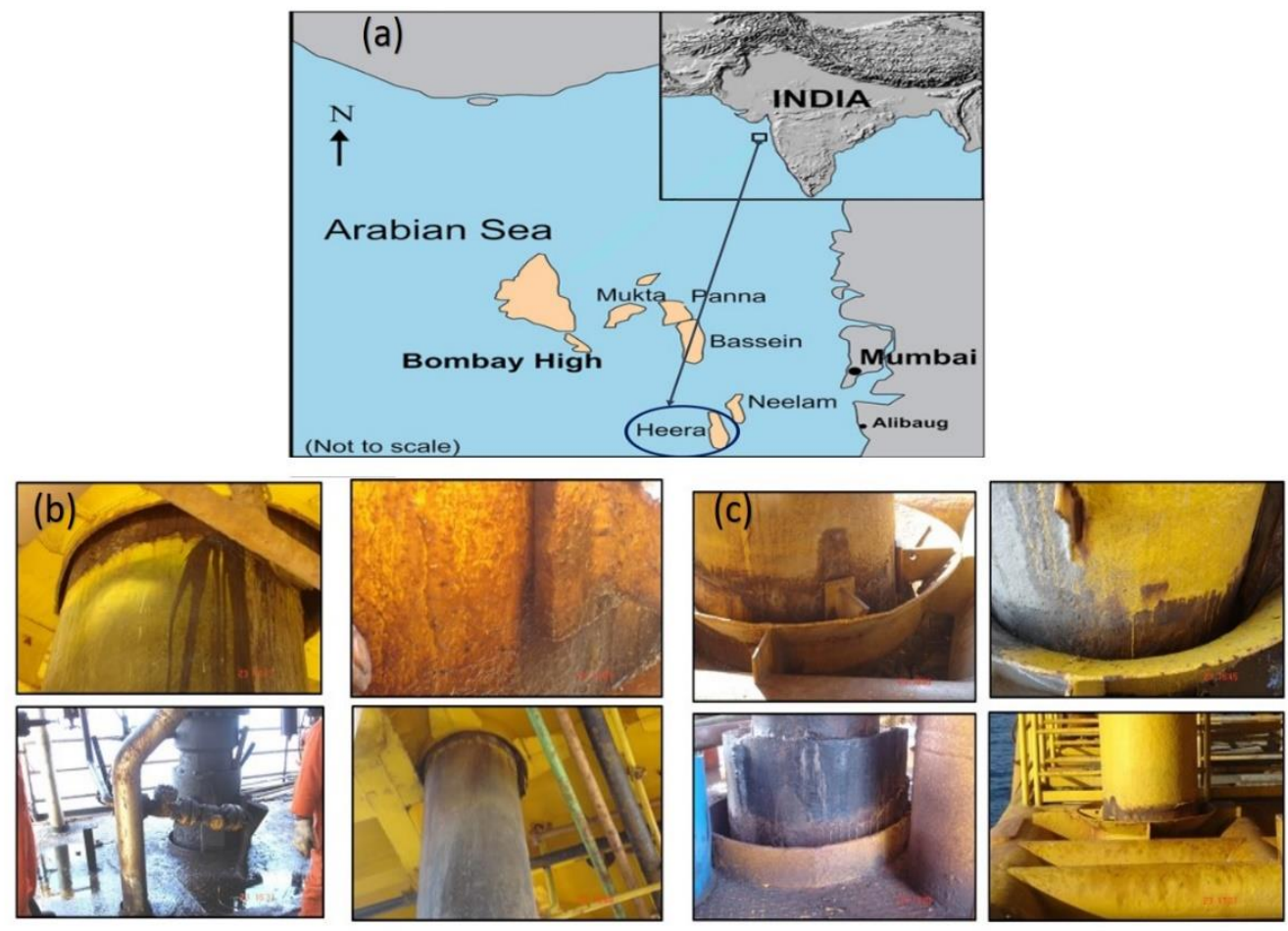

Figure 2. (a) Location map of the North-Heera field in the Mumbai offshore, (b) Noticeable subsidence occurred in one of the platforms and wells, (c) Upliftment of the offshore wells and platform in Mumbai offshore.

Formation-5 and 6 are the producing zones that have foraminiferal wackestone with patchy and vuggy porosity. Formation-7 has alternatively deposited layers of clay, shale, sand, and siltstone. Finally, the basement consists of hard and greenish granitic layers (formation-8). DGH India provided these lithology details for this study. The lithostratigraphic data was analyzed initially from the well logs, cores samples, and drill cuttings to include in the workflow (Figure 3) for constructing the geomechanical models.

\section{Section - I: Seismic Data Processing}

Interest in seismic inversion methods has increased over the last two decades for the reason that seismic inversion obtains subsurface rock physical and elastic properties information from continuous seismic data sets. Seismic inversion surrogates the signature of seismic data associated with subsurface data, analogous to the subsurface acoustic and impedance models. A seismic inversion converts the contrasted seismic data to a model that confirms the geological and petrophysical boundaries in the subsurface (Veeken and Da Silva, 2004). Seismic inversion is broadly divided into two categories: post-start and pre-stack. In the post-stack seismic technique, a single trace volume is converted into acoustic impedance ( $\mathrm{P}$ - impedance) using seismic data. The pre-stack inversion technique uses multiple traces of a linear AVO model to transform seismic data into acoustic impedance. This study used pre-stack inversion because it provides promising outputs of $\mathrm{V}_{\mathrm{p}} / \mathrm{V}_{\mathrm{s}}$, shear impedance, and acoustic impedance, which identify the lithology facies more precisely over post-stack inversion (Moghanloo et al., 2018; Veeken and Da Silva, 2004). 3D prestack data of the Mumbai offshore Basin covering $200 \mathrm{~km}^{2}$ area was processed for corrections to 
obtain geomechanical properties. Outputs from the seismic inversion process help explain drainage areas, identification of sweet spots, and prospect ranking for field development. Seismic inversion was performed on the pre-stack seismic data using Hampson and Russell 9 software. Figure 3 shows the flow chart of the pre-stack seismic inversion using the initial model. Here, we have done the seismic inversion iteratively.

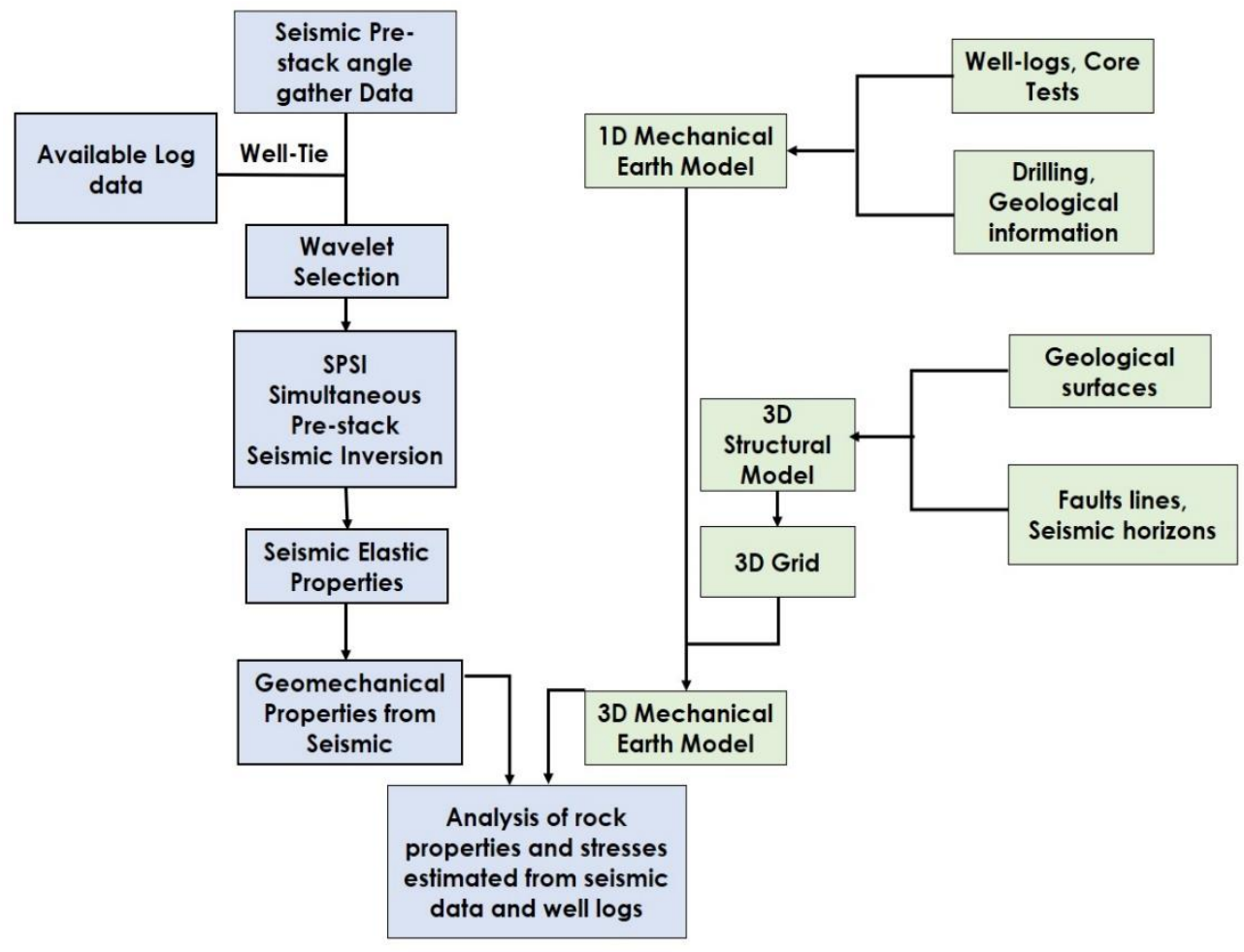

Figure 3. Workflow for the geomechanical properties estimation from seismic and well log data.

A pre-stack inversion method combines Common Depth Point (CDP) gathers and Amplitude Versus Offset (AVO) effects (Richards and Aki, 1980). A significant difference is observed in many cases during partial stacking on the top layer amplitude of the reservoir. Primary waves hold the lithology and the pore-fill information, while the fluid contents do not influence transverse Swaves (Öz Yilmaz, 2001). Geomechanical parameters like the PR, YM, Shear modulus, and Lame modulus are estimated from the seismic velocity variations and the formation density. The 3D prestack seismic inversion provides a better understanding of the rock's physical properties (porosity, saturation, permeability) and elastic properties (SM, LM, YM, PR, BI).

\subsection{Simultaneous Prestack Seismic Inversion (SPSI)}

Well to seismic tie is very significant for seismic data inversion and interpretation. A comparison is made at the well location between synthetic and seismic waves in the seismic inversion method. In well-tie analysis, interpreting the reflectors' waveform and amplitude at the well location depends on the quality of well logs and seismic data (Saberi, 2018). Generally, for tying log data to seismic data, impedance logs (sonic and density) are filtered by seismic wavelets (Ziolkowski et al., 1998). Signal-to-noise ratio, bandwidth, and data availability are essential seismic elements for 
well-tie (White and Simm, 2003). A few assumptions are made during wavelet extraction, such as zero-phase seismic data cube, Normal Random or Gaussian reflectivity series, and correctly determining time bulk-shift of synthetic trace. Generally, wavelet extraction falls into two categories: Auto Correlation (statistical method) and Weiner- Levinson (uses well data). A minimum phase seismic wavelet was estimated from seismic data using statistical methods. This wavelet was used to generate the synthetic seismogram at well locations. All the six horizons in the provided data were exported and loaded into the inversion project.

Inversion of seismic pre-stack data provides reliable compressional and shear velocities to predict the subsurface's lithology and fluid properties. We used the (Hampson et al., 2005, Mahadasu et al., 2021) SPSI in this study because it is the comprehensive inversion approach of (Simmons and Backus, 1996) and (Buland and Omre, 2003). In the inversion process, a window is operated at the selected well-tie locations to examine the inversion parameters. This method generates the velocity and density synthesis, which helps to compare the actual velocity and density at the well locations.

\subsection{Estimation of Elastic and Geomechanical Properties from Seismic Data}

Estimating elastic and geomechanical properties from seismic data provides insights into geomechanical aspects during drilling and hydrofracturing. Futuristic problems production-related subsidence of wellbores and lands can be analyzed from the rock models of the reservoir. Pimpendence and Z-impendence derived from seismic inversion generate elastic properties models. The following expressions are used for estimating elastic moduli of the rock.

Shear Modulus is calculated from the below-given expressions:

$\mu=\rho * V_{S}^{2}$

$\mu$ is shear modulus in GPa, $\rho$ and $V_{s}$ are formation's density $(\mathrm{gm} / \mathrm{cc})$ and shear wave velocity $(\mathrm{m} / \mathrm{s})$ of the subsurface.

$\lambda=\rho * V_{p}^{2}-2 \mu$

$\lambda$ is Lame's modulus in GPa, $\mu$ is shear modulus (GPa), $\rho$ and $V_{P}$ are density of formation $(\mathrm{g} / \mathrm{cc})$ and primary wave velocity $(\mathrm{m} / \mathrm{s})$ of the subsurface respectively.

Poisson's ratio is calculated from the primary wave and the secondary wave velocities derived from the seismic inversion model.

$v=\frac{\lambda}{2(\lambda+\mu)}$

$\nu$ is Poisson's ratio, $\mu$ and $\lambda$ are shear, and Lame's moduli (GPa).

$\mathrm{E}=2 \mu *(1+v)$

E is Young's modulus in GPa, $\mu$ and $\lambda$ are shear and Lame's moduli (GPa), respectively.

Generally, vertical stress, minimum, and maximum horizontal stresses are estimated for long 3Dseismic data. The subsurface stresses are estimated from the seismic data where the seismic waves intersected the rock at angles $\left(>40^{\circ}\right)$. In the calculation of the principal stresses, a few assumptions have made; those assumptions are Calibration of estimated stresses, assumed the field stress measurements are valid for this area, differential horizontal stresses create azimuthal anisotropy, the elasticity of the rocks from this basin follows the linear slip theory and its assumptions. Based 
on the above assumptions, the results of principal stresses are estimated. The following are the expressions for in-situ stress calculation:

$\sigma_{\mathrm{z}}=\sigma_{\mathrm{v}}(\mathrm{z})=\int_{0}^{\mathrm{z}} \mathrm{g} \rho(\mathrm{dh})$

$\sigma_{\mathrm{x}}=\sigma_{\mathrm{z}} \frac{v(1+v)}{1+\mathrm{EZ}_{\mathrm{N}}-v^{2}}$

$\sigma_{\mathrm{y}}=\sigma_{\mathrm{z}} * v\left(\frac{1+\mathrm{EZ} \mathrm{Z}_{\mathrm{N}}+v}{1+\mathrm{EZ}_{\mathrm{N}}-v^{2}}\right)$

$\sigma_{\mathrm{z}}$ is overburden stress, $\sigma_{\mathrm{x}}$ is minimum horizontal stress, and $\sigma_{\mathrm{y}}$ is maximum horizontal stresses calculated from seismic data. Where $\mathrm{g}$ is the acceleration due to gravity $\left(\mathrm{ft} / \mathrm{s}^{2}\right), \rho$ is the rock's density derived from seismic inversion $(\mathrm{g} / \mathrm{cc}) . v$ is Poisson's ratio, $\mathrm{E}$ is Young's modulus, and $\mathrm{Z}_{\mathrm{N}}$ is normal compliance. By definition, compliance is the ability of an object to yield elastically when a force is applied. Using a wide-angle approach, $Z_{N}$ is calculated (Downton and Roure, 2010). There are other important rock physical parameters used during hydrofracturing studies, one of those parameters is Differential Horizontal Stress Ratio (DHSR), which is given by below expression:

$\operatorname{DHSR}=\frac{\left(\sigma_{\mathrm{H}}-\sigma_{\mathrm{h}}\right)}{\sigma_{\mathrm{H}}}$

here $\sigma_{\mathrm{h}}$, and $\sigma_{\mathrm{H}}$ are minimum and maximum horizontal stresses derived from Equations (6) and (7).

\section{Section - II}

\subsection{Geomechanical Properties from Well-Logs}

Geomechanical studies play a crucial role in developing tectonically active areas and addressing the current problems in the industry (Zoback, 2007). Change in the stresses due to production and injection of fluids affect drilling, completion, and wellbore production improvement operations. Instress changes in the formations affect casing integrity, compaction, and shallow layers to shrink. Changes in pore pressure, stresses, and mechanical rock properties impact field development and production strategies. 3D MEM provides the stress, pore pressure, and elastic moduli for the complete block between the wells and zones where wells are not drilled (Vishkai et al., 2017). Comprehensive analysis of 1D and 3D geomechanical models associated with triaxial tests helps to achieve robust stress prediction and weak zones identification. 3D geomechanical models are constructed by integrating geological models, petrophysical data, and drilling and completion data. This study aims to develop an integrated approach by combining seismic surveys, experimental rock analysis, and mechanical earth modeling to address the possible causes of wellbore instability and subsidence related to post-production. Our study developed 1D and 3D geomechanical models for the North-Heera block in Mumbai offshore using the workflow shown in Figure 4. 


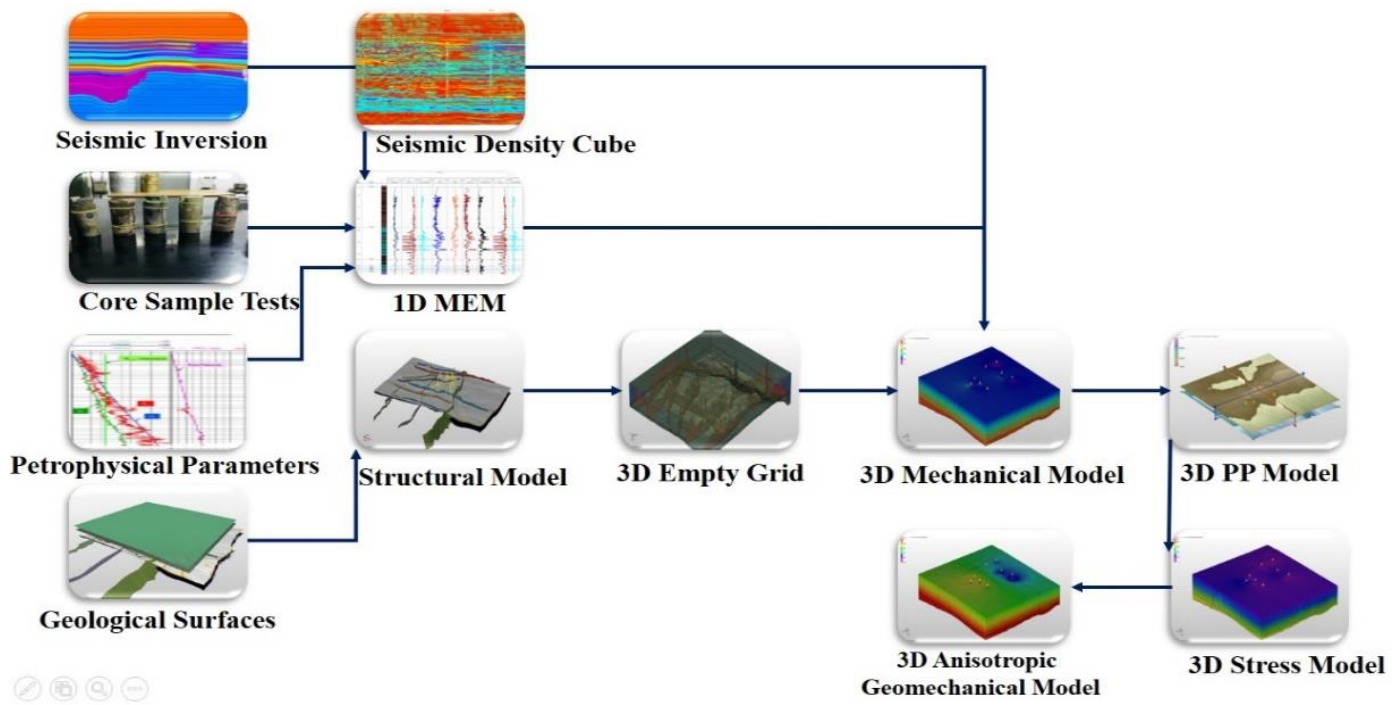

Figure 4. A detailed integrated workflow for developing 1D and 3D geomechanical models.

In the first step of the workflow, 1D Mechanical Earth Models for more than 40 oil wells were created from this producing offshore platform. Detailed Mechanical Earth Models (MEM) analysis carried out to avoid wellbore trajectories drilling through weak formation zones, which is discussed in the work of (Ambati et al., 2021). According to the geomechanical terms, the mechanical earth model is a numerical representation of stress and rock elastic properties for a specific stratigraphic section of a well in a field or basin (Araujo et al., 2010). The estimation of in-situ stresses for gas and oil wells requires almost the same data sets. Calculation of the pore pressure of gas wells requires more attention as abnormal pressure pockets or zones may be encountered when drilling through gas reservoirs (Aregbe, 2017). Rock elastic properties from well logs are estimated for the entire wellbore length using governing equations by taking lithology into significant consideration. Poison's ratio, Bulk modulus, Young's modulus are the elastic moduli determined for the wells, and the governing equations for calculations are given by Equations (9), (10), and (11) (Fjaer et al., 2008).

$v_{d y n}=\frac{V p^{2}-V s^{2}}{2 *\left(V p^{2}-V s^{2}\right)}$

$G_{d y n}=\rho *\left(V_{P}^{2}\right)$

$E_{\text {static }}=0.6722 *\left(E_{\text {dyn }}^{1.0573}\right)$

$v_{\mathrm{dyn}}, \mathrm{G}_{\mathrm{dyn}}$, and $\mathrm{E}_{\mathrm{dyn}}$ are the dynamic Poisson's ratio, Bulk modulus, and Young's modulus. $\mathrm{V}_{\mathrm{p}}, \mathrm{V}_{\mathrm{s}}$ are the compressional wave velocity and shear wave velocity, where $\rho$ is the bulk density of the formation. UCS was estimated by different empirical equations (Chang et al., 2006) by considering lithology.

In-situ stress estimation is essential for geomechanical analysis and interpretation. In our study, lithology-based estimation of in-situ stress is very significant for the anisotropic formations considering pore pressure, Young's modulus, Poisson's ratio, and Biot constant (Blanton and Olson, 1999; Molaghab et al., 2017; Nurhandoko, 2019; Zhang and Zhang, 2017). Accuracy of horizontal 
stresses profiles improved by considering the poroelastic horizontal strain model determining the magnitudes of minimum and maximum horizontal stresses; given as (Ambati et al., 2021):

$S_{\text {hmin }}=\frac{v}{1-v} \sigma_{v}+\frac{1-2 v}{1-v} \alpha P_{p}+\frac{E}{1-v^{2}} \varepsilon_{x}+\frac{v E}{1-v^{2}} \varepsilon_{y}$

$\mathrm{S}_{\mathrm{Hmax}}=\frac{v}{1-v} \sigma_{\mathrm{v}}+\frac{1-2 v}{1-v} \alpha \mathrm{P}_{\mathrm{p}}+\frac{\mathrm{E}}{1-v^{2}} \varepsilon_{\mathrm{y}}+\frac{v \mathrm{E}}{1-v^{2}} \varepsilon_{\mathrm{x}}$

$\varepsilon_{\mathrm{x}}=\frac{\sigma_{\mathrm{v}} \times \mathrm{v}}{\mathrm{E}}\left(\frac{1}{1-\mathrm{v}}-1\right)$

$\varepsilon_{\mathrm{y}}=\frac{\sigma_{\mathrm{v}} \times \mathrm{v}}{\mathrm{E}}\left(1-\frac{\mathrm{v}^{2}}{1-\mathrm{v}}\right)$

$\mathrm{P}_{\mathrm{p}}$ is interpreted pore pressure from well logs, $\alpha$ is Biot constant, $v$ is Poisson's ratio, $\sigma_{\mathrm{v}}$ is vertical stress, and $\mathrm{E}$ is Young's modulus. Here $\varepsilon_{\mathrm{x}}$ and $\varepsilon_{\mathrm{y}}$ are the compressional horizontal strain in the $\mathrm{X}-$ direction and extensional horizontal strain in the y-direction.

The construction of 3D geomechanical models necessitates a considerable amount of knowledge about lithology and geostatistics. The coordinates of the 3D grid developed in this study are X$11475 \mathrm{~m}, \mathrm{Y}-12525 \mathrm{~m}$, and Z-2700m. The step length considered was X-75m and Y-75m, covering $200 \mathrm{~km}^{2}$ area of the North-Heera field. After creating the 3D grid over the structural model using the wells, the elastic properties, strength parameters, and principal stresses were populated in the 3D grid. The Kriging geostatistical method was applied to map the properties to the grid or the surfaces. Ordinary kriging is the general and most commonly used geostatistical method for property mapping in surfaces and 3D grids, and it is more accurate than other kriging methods (GiaPham et al., 2019). This method estimates the value at a target point using a value at the nearest point in the neighborhood (Wackernagel, 1995).

Using the property correlations and spatial locations between the target and reference points, the kriging method gives highly accurate interpolation estimation (Fertl et al., 1976; Hodam et al., 2017; Liu et al., 2017; Paramasivam and Venkatramanan, 2019). UCS models were generated after generating a 3D grid, pore pressure, fracture, and stresses.

\section{Results and Discussion}

Model-based inversion helps generate P-impedance and Z-impedance, which can be further used for generating rock property models. In our study, pre-stack data of the North-Heera field was used for model-based inversion. Three vertical wells were used for the well-tie and inversion analysis, of which two are exploratory wells (well-1 \& 2), and one is a producing well (well-3). The inversion process created synthetic density and velocity waves and helped in the comparison of synthetic data at the well location.

Lame's parameters consist of two parameters which are Lame moduli and Shear modulus. Lame modulus $(\lambda)$ is also called a lame first parameter, which provides the material's stiffness or formation. Shear modulus $(\mu)$ is defined as shear stress to shear strain; this also focuses on the material's stiffness matrix. The two parameters together provide information on the elastic properties of homogeneous rock formation. Shear modulus calculated from the seismic data is illustrated in Figure 5; property variations ranging from 1.2 to $2.4 \mathrm{GPa}$ are noticed in the entire volume. 
Seismic to well tie is the foremost step in seismic inversion and was carried out for angle stacks of $\left(5^{\circ}-15^{\circ}\right),\left(15^{\circ}-25^{\circ}\right)$, and $\left(25^{\circ}-35^{\circ}\right)$ by employing angle-dependent wavelets with two wavelet estimation methods at each wellbore location. These statistical wavelets and synthetic seismograms were generated by employing the reflectivity from logging data (De-Macedo et al., 2017). With this synthetic seismogram, seismic to well-tie operation was conducted in each location until a better correlation between actual seismic data and synthetic seismic data was obtained (Deng et al., 2018). Then well-based wavelets were estimated by finding the operator that convolved with the well's reflectivity at each well (Palmeira and Farrell, 1982). The correlation between original data and synthetic data was found to be 0.915796 . In the procedure, deterministic wavelets for other wells were extracted. Inversion analysis was performed along with a target window between 0$4000 \mathrm{~ms}$ for angle range 5 -35 degrees for well-1. Based on inversion analysis, we selected the best wavelet which had the minimum error. Multiple checks were conducted on wells 2 and 3 for extracting the wavelet before inversion. $\mathrm{Z}_{\mathrm{p}}, \mathrm{Z}_{\mathrm{s}}$, Dn, $\mathrm{V}_{\mathrm{p}} / \mathrm{V}_{\mathrm{s}}$ ratio are the primary outputs developed from the SPSI inversion. The inversion extracted parameters generate the rock elastic properties and geomechanical properties for the basin or field. In this study, rock properties such as shear modulus (SM), Lame's modulus (LM), Poisson's ratio (PR), and Young's modulus (YM) were generated from the Equations (1) - (4).

Many significant lower values are noticed at the shallow depths of $200-400 \mathrm{~m}$. Figure 6 shows the Lame's parameter one ( $\lambda$ ). There is a contrast in the values of the $\lambda$ all over the volume, but at a depth of 600-750m interval, higher and lower values are noticed. Depth interval $(600-800 \mathrm{~m})$ is a transition zone from shale to carbonate formation, and a low range of Poisson's ratio values is identified, as shown in Figure 7. The PR of the entire volume ranges from $0.23-0.47$. Generally speaking, PR ranges from 0- 0.5 in the sedimentary rocks, and PR in high porous carbonates is low compared to shale formation ( $\mathrm{Li}$ and Zhao, 2014). Young's modulus volume generated based on seismic inversion results is shown in Figure 8; YM values from the volume have been observed to be distributed from a range of 5.4 to $28.7 \mathrm{GPa}$. A combination of both higher and lower YM values is observed at the shallow zones and the transition zone of shale and carbonates. Brittleness is a vital rock property that helps in fracturing and other injection studies. It is generally measured as a percentage known as the brittleness index (BI). We have computed the BI of the subsurface layers of the reservoir block using seismic data. BI of this block varies with contrast ranging from 2-35 $\%$; shallow layers are shale, and claystone possesses a BI of 2-10\%, and the production zones are carbonate and have a BI of 5-15\% shown in Figure 9. Sedimentary layers below the production zones are composed of basalt and granite with BI above $25 \%$. Overall, a significant contrast in the $\mathrm{BI}$ is noticed at the shallow depths and 650-900m depth interval. (and depth between 650 and $900 \mathrm{~m})$. The approach of combining seismic, well logs, and drilling data enabled the development of 3D geomechanical models for an area of $200 \mathrm{~km}^{2}$. Figures 3 and 4 illustrate the methodology and workflow used to build this 3D model for the offshore reservoir block. As a first step, we developed 1D MEM for 40 oil and gas producing wells. Overburden stress in 1D MEM was calculated from the density logs using Equation (5), and the horizontal stresses Shmin and SHmax were calculated from Equations (12) - (15). Calculation of rock properties from well logs is a lithology-based approach (Koutsabeloulis and Zhang, 2009; Zhang, 2019), where we considered the constants based on the lithology of the surface and generated the rock properties using the governing Equations (9) - (11).

Five formation tops were used for creating a stratigraphic model, and 22 faults were incorporated to create a watertight structural model. In order to cover the total thickness of the formation layers, 140 sub-layers were created in the stratigraphic model. Each sub-layer has a different thickness but 
the same lithology and similar structure. A 3D structural grid was built using a hybrid grid approach, which is the most reliable option for irregular topographies in subsurface modeling. Forty wells drilled in this reservoir from different platforms were used for generating 3D geomechanical models. Rock properties derived from the1D MEMs were populated into the 3D grid using the ordinary kriging approach (Al-Ruwaili and Chardac, 2003; Fung et al., 1994; Janis et al., 2016). 3D elastic moduli (Young's modulus, Poison's ratio, Bulk modulus) models were created.

On first observation, the overburden pressure in Figure $10, S_{\mathrm{v}}$, does not show any significant variation in the gradient or the spatial distribution. Minor variations in horizontal stresses were observed with depth, and shallow depth rock layers have the values of $\sigma_{\text {hmin }}=800 \mathrm{psi}, \sigma_{\mathrm{Hmax}}=$ 1000psi without much deviation from the normal shown in Figures 11 and 12 but significant deviations in the stresses are seen at the depths of $700 \mathrm{~m}-1000 \mathrm{~m}$.

Spatial variation in the geomechanical properties such as Young's modulus, Poisson's ratio, and UCS are shown in Figure 13. In the 3D model's cross-section view at $650 \mathrm{~m}$ depth, as shown in Figure 11, a noticeable contrast in geomechanical properties distribution is observed. Young's Modulus at this depth varies spatially between 5GPa-15GPa. The Poisson's Ratio varies between $0.32-0.45$ at this depth, and UCS has the value of $7 \mathrm{MPa}-10 \mathrm{MPa}$ at $650 \mathrm{~m}$, except the contour indicates a low strength. Figure 14 illustrates the pore pressure distribution in the 3D grid, which was achieved by the kriging interpolation method. Correlation of the wells was necessary to distribute pore pressure into the 3D volume.

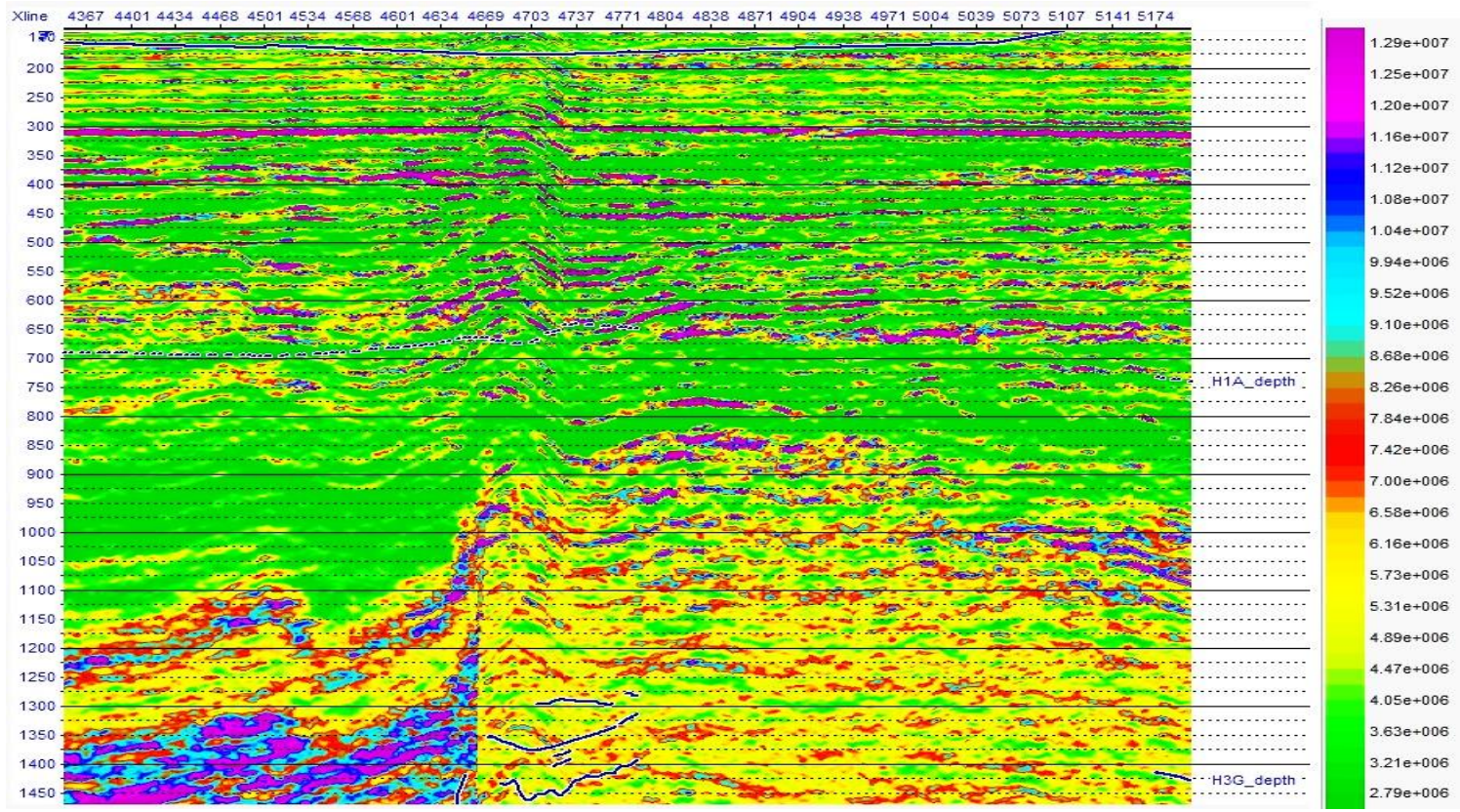

Figure 5. Illustrates the shear modulus of the block calculated from the seismic inversion. 


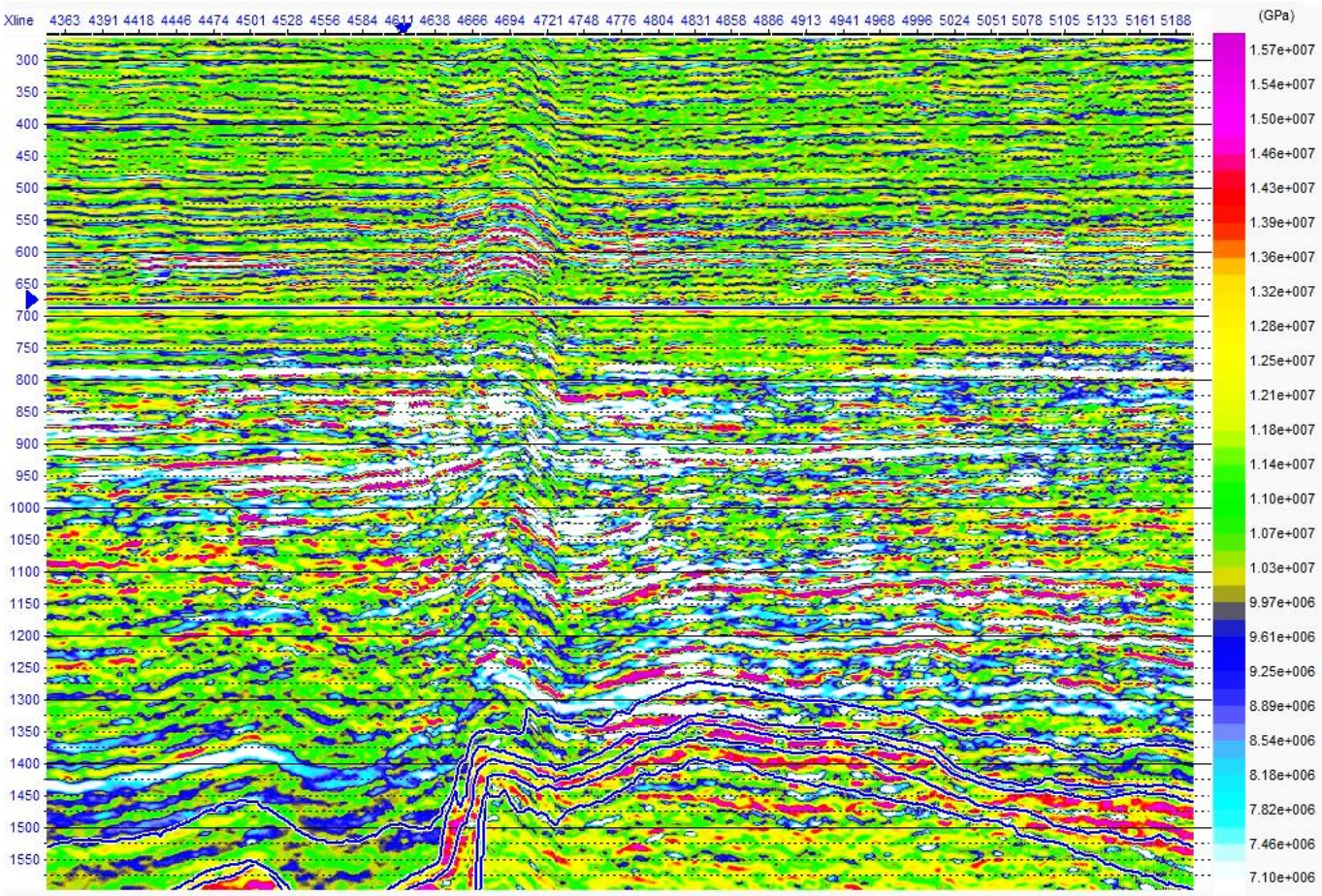

Figure 6. Illustrates the lame modulus of the subsurface layers of reservoir block calculated from the seismic inversion.

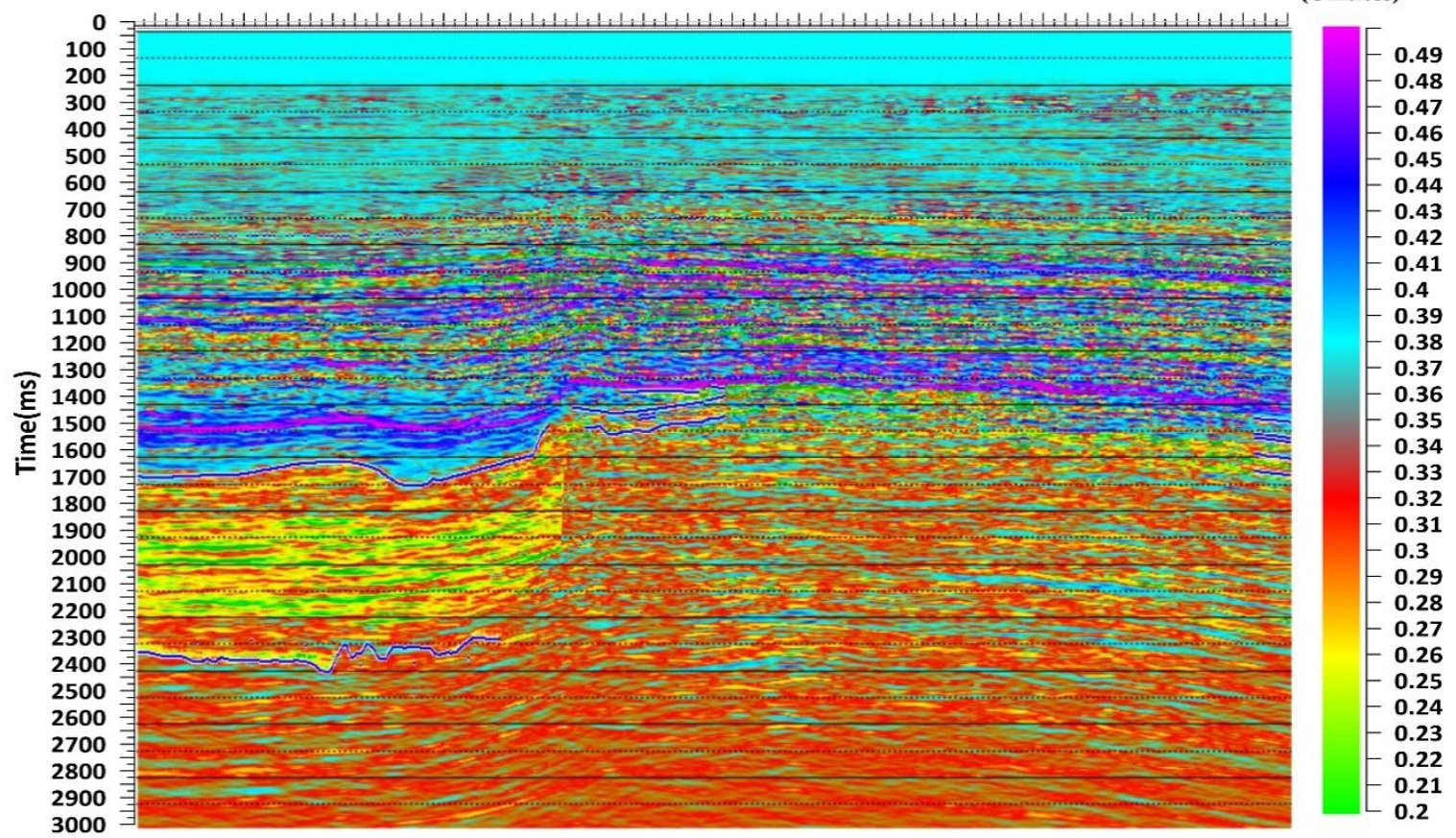

Figure 7. Poisson's ratio of the subsurface of the North-Heera field calculated from the seismic inversion. 


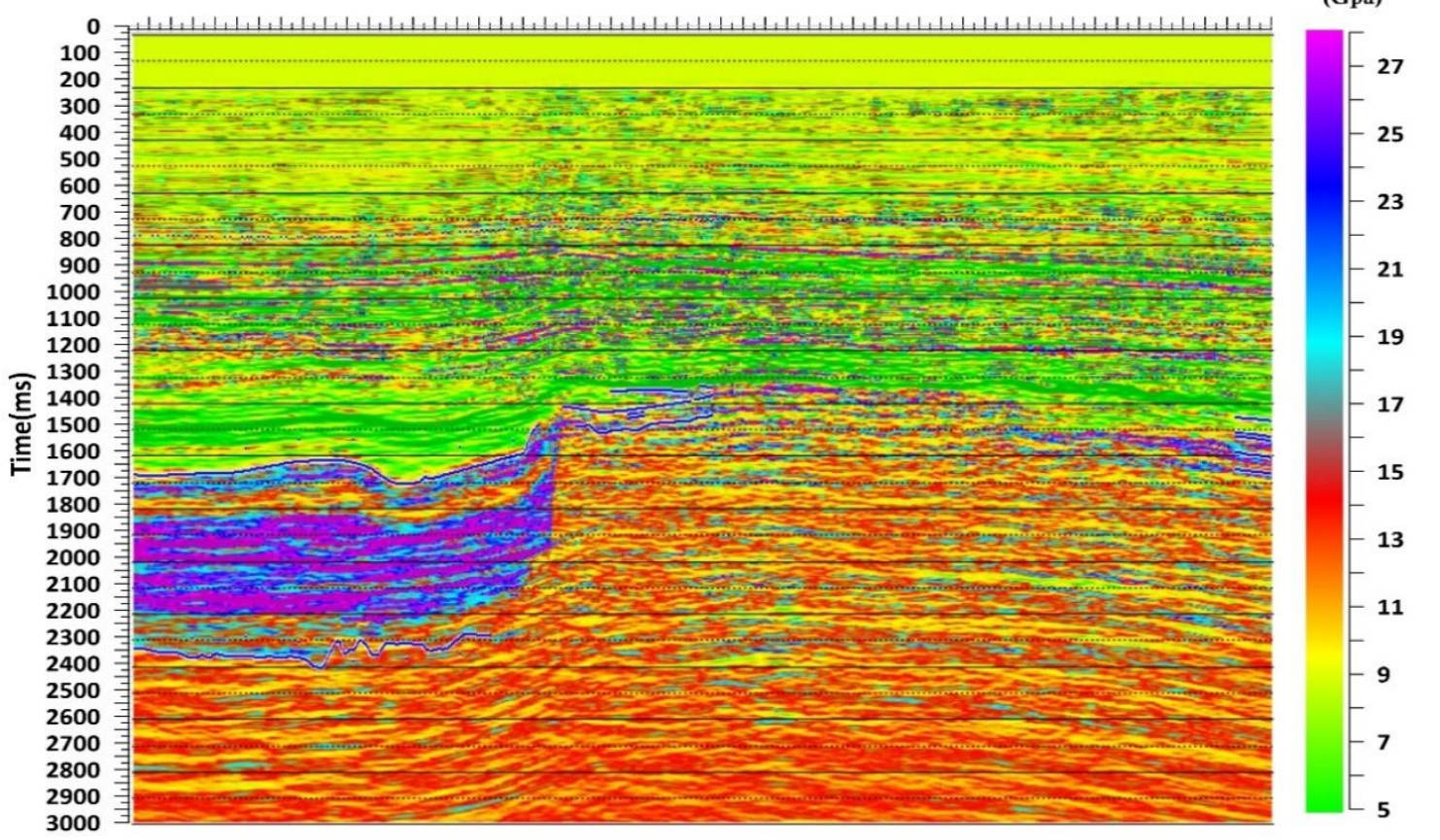

Figure 8. Young's modulus of the subsurface of the North-Heera field calculated from the seismic inversion.

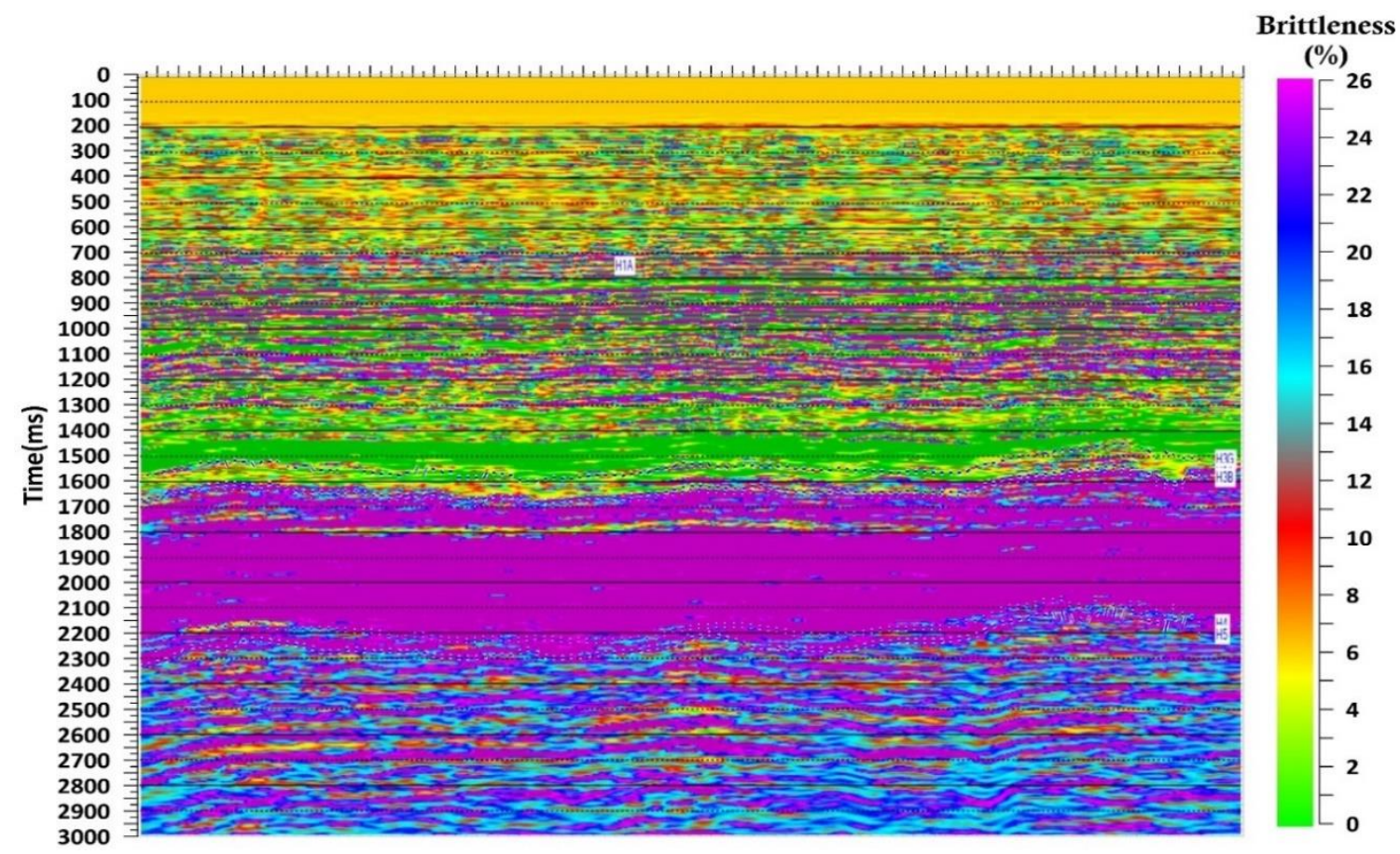

Figure 9. Illustrates the brittleness index computed from the seismic data after inversion ranges from 3-40 $\%$ in the subsurface layers of the study block. 


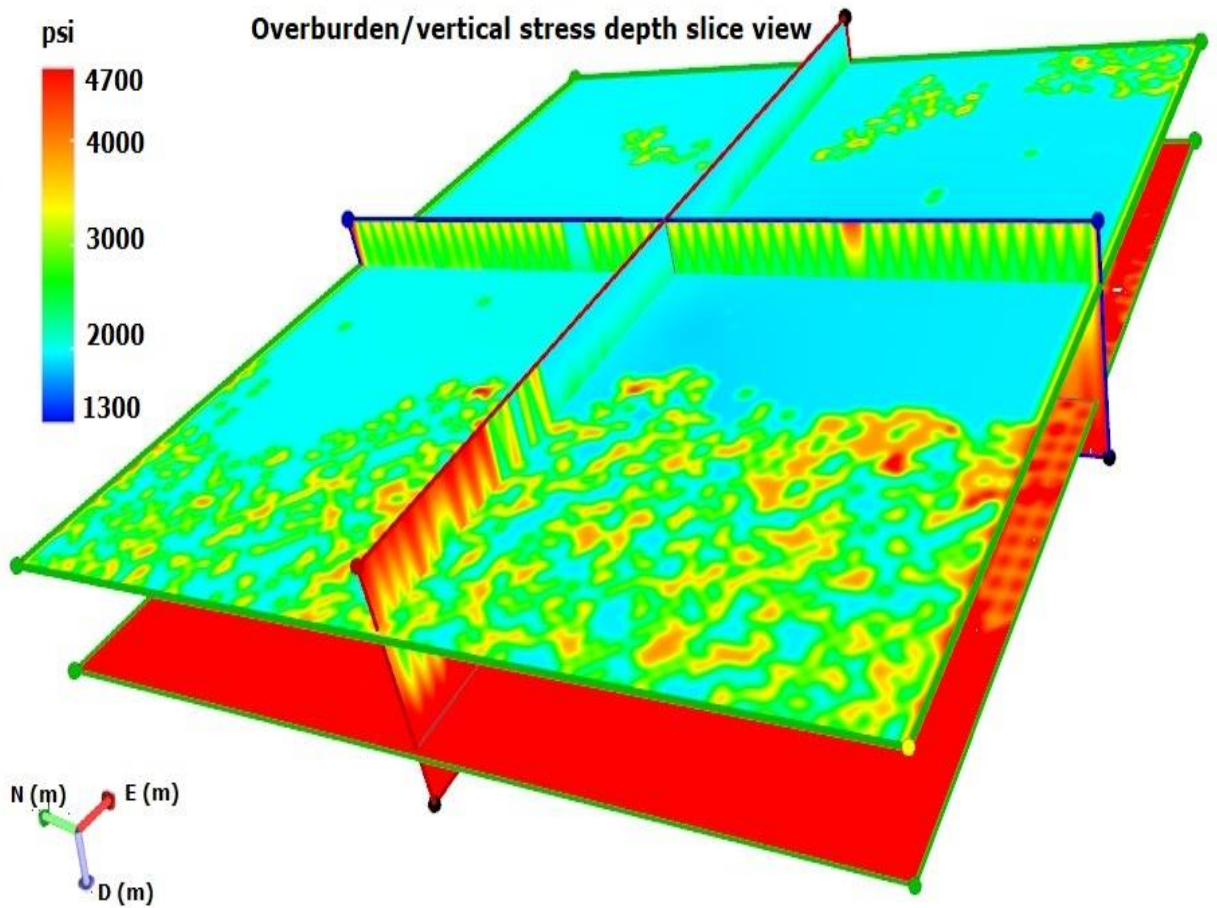

Figure 10. 3D depth slice view of overburden pressure ( $\mathrm{Sv}$ ) distribution at is $430 \mathrm{~m}$ and $1636 \mathrm{~m}$.

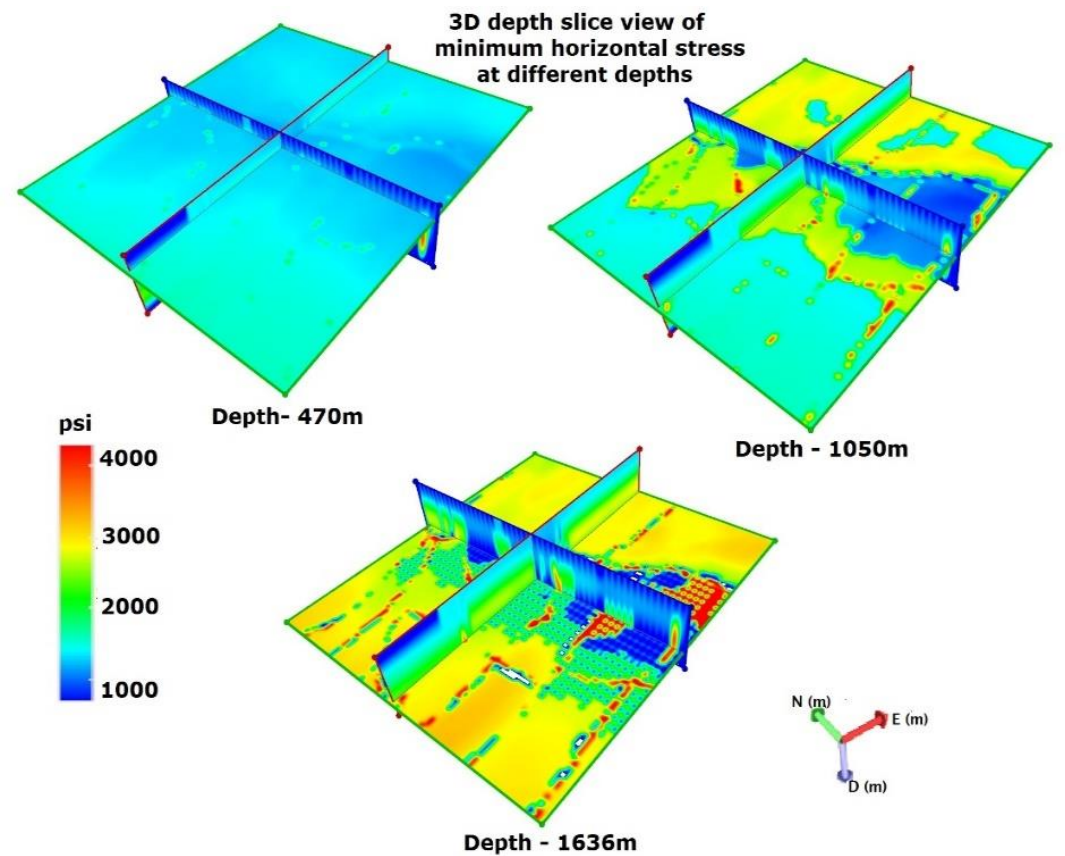

Figure 11. 3D view of minimum horizontal stress variation in the spatial directions at $400 \mathrm{~m}, 1050 \mathrm{~m}$, and $1636 \mathrm{~m}$. 


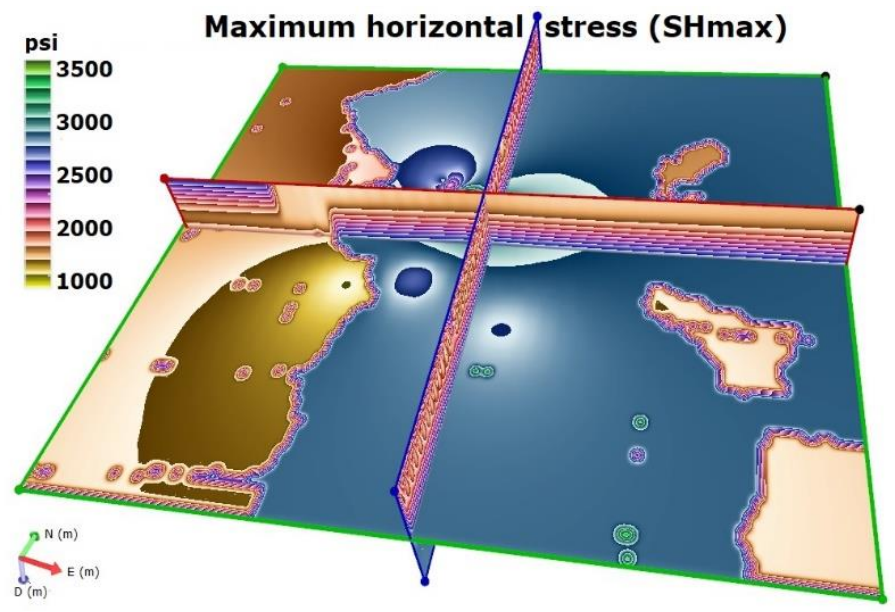

Figure 12. Interpreted maximum horizontal stress from wellbore breakouts and well logs.

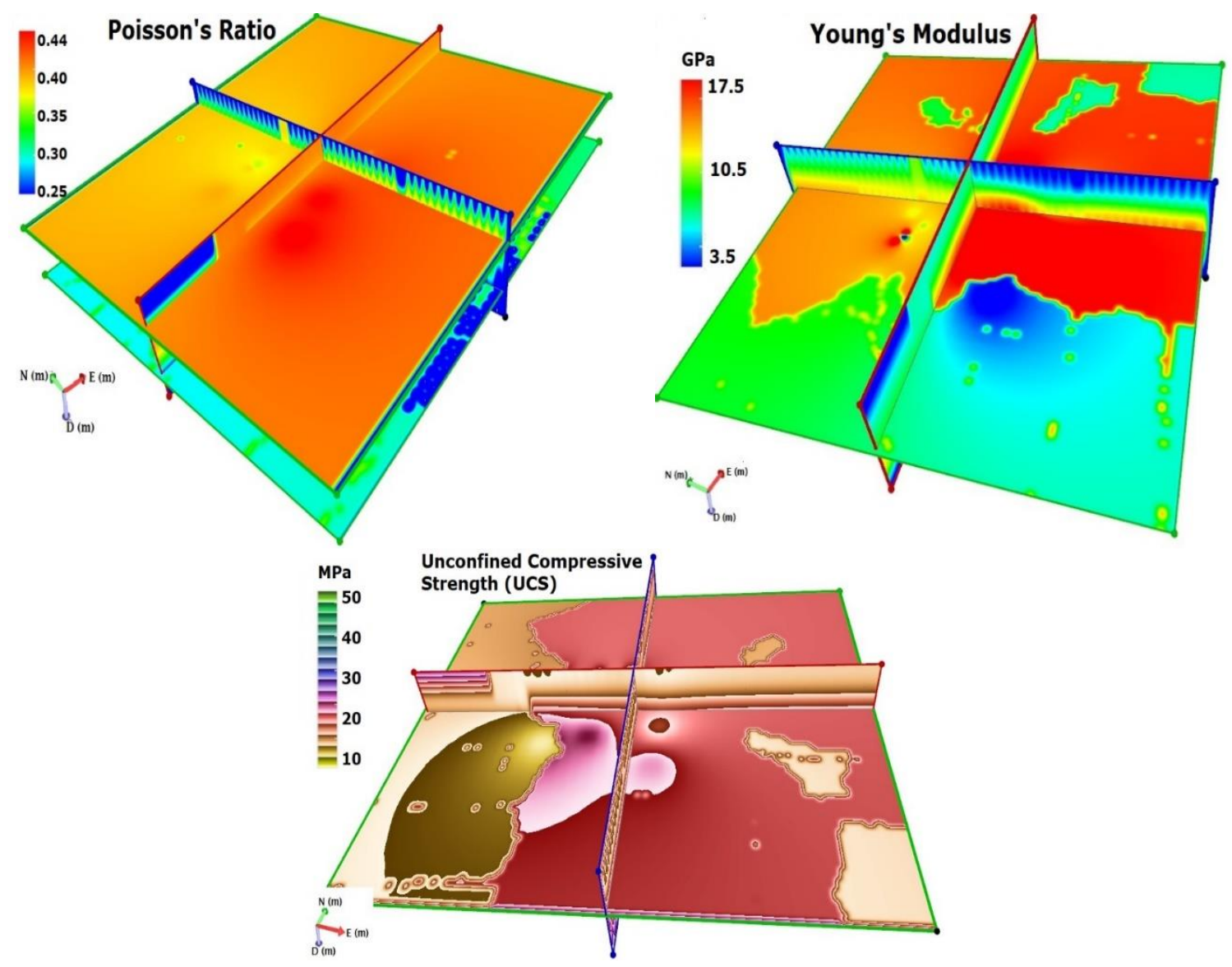

Figure 13. Depth slice view of 3D spatially distributed elastic moduli and rock strength properties (a) Poisson's ratio, (b) Young's Modulus, and (c) UCS. 

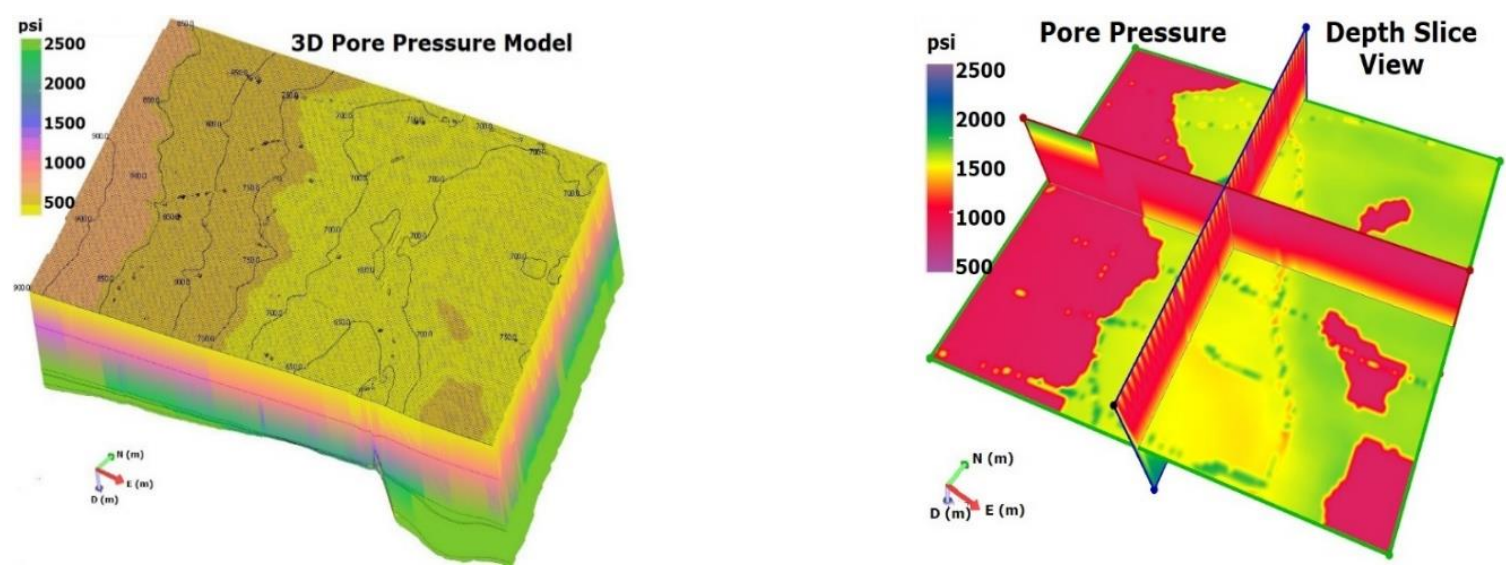

Figure 14. 3D distribution of interpreted pore pressure with contours on the surface layer, the right side is depth slice of pore pressure at $1036 \mathrm{~m}$.

\section{Conclusions}

Geomechanical analysis for this field was carried out for the first time in this field (North-Heera). We have integrated multiple domains (geophysics, geomechanical, and petrophysics) to thoroughly analyze and interpret this block for addressing geomechanical issues in the past and the near future. Prestack seismic data was used for well-tie analysis and SPSI. Wavelets were extracted after QC of the well-tie process. Well-based wavelets were then estimated by finding the operator that convolved with the well's reflectivity at each well, and deterministic wavelets were extracted. Rock elastic properties and geomechanical properties for the field were generated using seismic inversion models. Geomechanical property models have been analyzed and interpreted; the models were observed to find the contrast of values at shallow depths and intervals of $600-800 \mathrm{~m}$. Initially, in this study, 1D geomechanical models were constructed for 40 exploratory and development wells. Interpreting and developing $1 \mathrm{D}$ and $3 \mathrm{D}$ pore pressure models involved seven vertical wells from different offshore platforms. The 3D model was constructed with an area of more than $200 \mathrm{~km}^{2}$ for this field. Horizontal stresses are low, and narrow pore pressure windows are observed at shallow depths. Normal faulting regime $\left(\sigma_{\mathrm{v}}>\sigma_{\mathrm{Hmax}}>\sigma_{\mathrm{hmin}}\right)$ exists at the wellbore vicinities, and Shmin was calibrated with LOT data. 3D spatial distribution of geomechanical properties in 3D grids was carried out by the kriging method. Populating geomechanical parameters in the 3D grids helped identify the significant variation in the spatial reservoir and rock properties. Depth slice view, the spatial distribution of rock strength parameters (PR, UCS, YM) was low at the shallow depths and transition zone of shale and carbonates. The developed geomechanical models can be used for planning future wellbore trajectories. The stress models and fracture models can help maintain future injection pressures into the reservoir. Seismic-derived geomechanical models and stress models were compared with geomechanical models derived from the well logs. The study provides insights into stress distribution around wellbores and identification of weakzones, which is essential for hydrofracturing jobs, IOR and EOR methods near future and far future applications. 4D geomechanical studies using timely updated pore pressures and horizontal stresses can help optimize reservoir management and avoid catastrophic events. 
Conflict of Interest

The authors declare no potential conflict of interest regarding the publication of this work. Besides, the ethical issues, including plagiarism, informed consent, misconduct, data fabrication and, or falsification, double publication and, or submission, and redundancy have been entirely witnessed by the authors.

\section{Acknowledgements}

This paper's authors extend their gratitude to the Oil and Natural Gas Corporation Limited (ONGC), CGG (Hampson Russell software), and Baker Hughes for their continuous support to make this research work possible. We also thank ONGC-Mumbai and the Centre of Excellence in Well Logging Technology (CEWELL)-Baroda for providing data for this research under the PAN IIT ONGC project. We thank Mr. Priti Prasad Deo, former executive director of CEWELL of ONGC, for his continuous support and valuable discussions.

\section{References}

Al-Ruwaili, S.B., \& Chardac, O. (2003). 3D Model for rock strength \& in-situ stresses in the khuff formation of ghawar field, methodologies \& applications. Middle East Oil Show, 13, 491-499.

Ambati, V., Mahadasu, N.B., \& Nair, R.R. (2021). Reservoir wellbore stability analysis and weak zones identification using the 1d mem, swelling tests and ucs: a case study from mumbai offshore, India. Arabian Journal for Science and Engineering. https://doi.org/10.1007/s13369-021-05530-w.

Araujo, E., Alcalde, R., Mateus, D., Fernandez-Ibañez, F., Sheridan, J., Ward, C., Brudy, M., Alvarellos, J., Ordonez, L.Y., \& Cardona, F. (2010). Drilling optimization using 3D geomechanical modeling in the llanos orientales basin, Colombia. SPE Latin American and Caribbean Petroleum Engineering Conference Proceedings, 1, 562-573. Lima, Peru.

Aregbe, A.G. (2017). Wellbore stability problems in deepwater gas wells. World Journal of Engineering and Technology, 05(04), 626-647. https://doi.org/10.4236/wjet.2017.54053.

Blanton, T.L., \& Olson, J.E. (1999). Stress magnitudes from logs: effects of tectonic strains and temperature. SPE Reservoir Evaluation \& Engineering, 2(01), 62-68.

Buland, A., \& Omre, H. (2003). Bayesian linearized AVO inversion. Geophysics, 68(1), 185-198. https://doi.org/10.1190/1.1543206.

Chang, C., Zoback, M.D., \& Khaksar, A. (2006). Empirical relations between rock strength and physical properties in sedimentary rocks. Journal of Petroleum Science and Engineering, 51(3-4), 223-237.

De-Macedo, I.A.S., Da Silva, C.B., De Figueiredo, J.J.S., \& Omoboya, B. (2017). Comparison between deterministic and statistical wavelet estimation methods through predictive deconvolution: seismic to well tie example from the North Sea. Journal of Applied Geophysics, 136, 298-314.

Deng, W., Wang, Y., \& Morozov, I.B. (2018). A simple wavelet-estimation approach for well-log to seismic tying.

Downton, J., \& Roure, B. (2010). Azimuthai simultaneous elastic inversion for fracture detection. SEG Technical Program Expanded Abstracts 2010, 263-267. https://doi.org/10.1190/1.3513389.

Dusseault, M.B. (2011). Geomechanical challenges in petroleum reservoir exploitation. KSCE Journal of Civil Engineering, 15(4), 669-678.

Fertl, W.H., Chilingarian, G.V., \& Rieke, H.H. (1976). Abnormal formation pressure environments. In Developments in Petroleum Science, (Vol. 2, Issue C, pp. 1-48).

Fjaer, E., Holt, R.M., Horsrud, P., Raaen, A.M., \& Risnes, R. (2008). Petroleum related rock mechanics. Developments in Petroleum Science (2nd ed., Vol. 53).

Fjaer, E., Holt, R.M., Horsrud, P., Raaen, A.M., \& Risnes, R. (1992). Petroleum related rock mechanics. Developments in Petroleum Science (1st ed., Vol. 33). 
Fung, L.S.K., Buchanan, L., \& Ravi, S. (1994). Hybrid-CVFE method for flexible-grid reservoir simulation. SPE Reservoir Engineering, 9(03), 188-194. https://doi.org/10.2118/25266-PA.

Gia-Pham, T., Kappas, M., Van Huynh, C., \& Hoang Khanh Nguyen, L. (2019). Application of ordinary kriging and regression kriging method for soil properties mapping in hilly region of central Vietnam. ISPRS International Journal of Geo-Information, 8(3), 147.

Hampson, D.P., Russell, B.H., \& Bankhead, B. (2005). Simultaneous inversion of pre-stack seismic data. SEG Technical Program Expanded Abstracts 2005, 1633-1637. https://doi.org/10.1190/1.2148008.

Hodam, S., Sarkar, S., Marak, A.G.R., Bandyopadhyay, A., \& Bhadra, A. (2017). Spatial interpolation of reference evapotranspiration in India: comparison of IDW and kriging methods. Journal of The Institution of Engineers (India): Series A, 98(4), 511-524.

Janis, M., Liu, J., Ghassemi, A., \& Center, S.E. (2016). Reservoir geomechanics model for egs. In Geothermal Resources Council Annual Meeting. US Department of Energy, 40, 345-352.

Koutsabeloulis, N., \& Zhang, X. (2009). 3D Reservoir geomechanical modeling in Oil/Gas field production. SPE Saudi Arabia Section Technical Symposium. https://doi.org/10.2118/126095-MS.

Li, M., \& Zhao, Y. (2014). Prestack seismic inversion and seismic attribute analysis. Geophysical Exploration Technology: Applications in Lithological and Stratigraphic Reservoirs. Elsevier. pp. 199219.

Liu, Z., Guo, Y., Du, S., Wu, G., \& Pan, M. (2017). Research on calibrating rock mechanical parameters with a statistical method. Plos One, 12(5), e0176215. https://doi.org/10.1371/journal.pone.0176215.

Mahadasu, N.B., Ambati, V., \& Nair, R.R. (2021). Seismic lithofacies distribution modeling using the single normal equation simulation (SNESIM) algorithm of multiple-point geostatistics in upper Assam basin, India. International Journal of Mathematical, Engineering and Management Sciences, 6(3), 805-823.

Moghanloo, H.G., Riahi, M.A., \& Bagheri, M. (2018). Application of simultaneous prestack inversion in reservoir facies identification. Journal of Geophysics and Engineering, 15(4), 1376-1388.

Molaghab, A., Taherynia, M.H., Fatemi Aghda, S.M., \& Fahimifar, A. (2017). Determination of minimum and maximum stress profiles using wellbore failure evidences: a case study - a deep oil well in the southwest of Iran. Journal of Petroleum Exploration and Production Technology, 7(3), 707-715.

Nurhandoko, B.E.B. (2019). Estimation strategy of subsurface stress Shmin and Shmax in borehole by combining cross-dipole sonic data and seismic rock physics laboratory.

Öz Yilmaz. (2001). Front matter. In Seismic Data Analysis: Processing, inversion, and interpretation of seismic data. Society of Exploration Geophysicists, (pp. i-xxiv).

Paramasivam, C.R., \& Venkatramanan, S. (2019). An introduction to various spatial analysis techniques. In GIS and Geostatistical Techniques for Groundwater Science, (pp. 23-30). Elsevier.

Palmeira, R.A.R., \& Farrell, R.C. (1982). Seismic wavelet extraction using sonic log data. In SEG Technical Program Expanded Abstract, 74-75. https://doi.org/10.1190/1.1827159.

Rana, S. (2008). Facts and data on environmental risks - oil and gas drilling operations. In SPE Asia Pacific Oil and Gas Conference and Exhibition. Perth, Australia. All Days.

Richards, P.G., \& Aki, K. (1980). Quantitative seismology: theory and methods (Vol. 859). New York: Freeman.

Saberi, M.R. (2018). Rock-physics-assisted well-tie analysis for structural interpretation and seismic inversion. The Leading Edge, 37(12), 908-914. https://doi.org/10.1190/tle37120908.1.

Simmons, J.L., \& Backus, M.M. (1996). Waveform-based AVO inversion and AVO prediction-error. Geophysics, 61(6), 1575-1588. https://doi.org/10.1190/1.1444077. 
Veeken, P.C.H., \& Da Silva, M. (2004). Seismic inversion methods and some of their constraints. First Break, 22(6). https://doi.org/10.3997/1365-2397.2004011.

Vishkai, M., Wang, J., Wong, R.C.K., Clarkson, C.R., \& Gates, I.D. (2017). Modeling geomechanical properties in the montney formation, Alberta, Canada. International Journal of Rock Mechanics and Mining Sciences, 96, 94-105.

Wackernagel, H. (1995). Ordinary kriging. In: Multivariate Geostatistics, (pp. 74-81). Springer, Berlin, Heidelberg. https://doi.org/10.1007/978-3-662-03098-1_11.

White, R.E., \& Simm, R. (2003). Tutorial: good practice in well ties. First Break, 21(10). https://doi.org/10.3997/1365-2397.21.10.25640.

Zhang, J.J. (2019). In situ stress regimes with lithology-dependent and depletion effects. In: Zhang, J.J. (ed.), Applied Petroleum Geomechanics, (pp. 163-185), Gulf Professional Publishing. ISBN 9780128148143, https://doi.org/10.1016/B978-0-12-814814-3.00005-8.

Zhang, Y., \& Zhang, J. (2017). Lithology-dependent minimum horizontal stress and in-situ stress estimate. Tectonophysics, 703-704, 1-8. https://doi.org/10.1016/j.tecto.2017.03.002.

Ziolkowski, A., Underhill, J.R., \& Johnston, R.G.K. (1998). Wavelets, well ties, and the search for subtle stratigraphic traps. Geophysics, 63(1), 297-313. https://doi.org/10.1190/1.1444324.

Zoback, M.D. (2007). Reservoir geomechanics. Cambridge University Press.

Original content of this work is copyright (C) International Journal of Mathematical, Engineering and Management Sciences. Uses under the Creative Commons Attribution 4.0 International (CC BY 4.0) license at https://creativecommons.org/licenses/by/4.0/ 